REVIEIV

\title{
NEUROREGULATORY EFFECTS OF NICOTINE
}

\author{
OVIDE F. POMERLEAU' ${ }^{1}$ and JOHN ROSECRANS ${ }^{2}$
}

1Behavioral Medicine Program, Department of Psychiatry, University of Michigan, Ann Arbor, Michigan, and 2Department of Pharmacology and Toxicology, Virginia Commonwealth University, Richmond, Virginia, USA.

(Recewed 18 October 1988: in final form 3 July 1989)

\begin{abstract}
SUMMARY
The impact of nicotine on the central nervous system is, in an important sense, neuroregulatory, with cascading effects on physiological and biochemical function as well as on behavioral activity. Accordingly, the neurotransmitter and neuroendocrine effects of nicotine constitute a critical part of its biological action, which includes reinforcing as well as pathophysiological consequences. This review focuses on nicotine's effects on cholinergic and non-cholinergic nicotine receptors and on the responses of catecholamines, monoamines, hypophyseal hormones, and cortisol. The contribution of critical variables, such as timing and duration of neuroregulator release and the patterns that make up the total response, is still largely unknown, particularly with regard to the effects of environmental context, history of nicotine use, and mode of administration. The evidence suggests that by altering the bioavailability of the above-listed neuroregulators, nicotine serves as a pharmacological "coping response", providing immediate though temporary improvement in affect or performance in response to environmental demands. Much of what is known to date is based on studies involving the administration of agonists and antagonists under different environmental conditions. Newer technological approaches such as autoradiography and positron emission tomography show potential for determining the neuroregulatory patterns involved and specifying nicotine's locus of action relevant to its behavioral and physiological effects.
\end{abstract}

\section{INTRODUCTION}

A REVIEW of the pharmacological effects of nicotine makes clear that the drug has powerful direct and indirect effects upon a number of neuroregulatory systems. In an important sense, the impact of nicotine on the central nervous system is neuroregulatory, with cascading effects on physiological and biochemical function as well as on behavioral activity (Balfour, 1982; Hall, 1982; Clarke, 1987; United States Department of Health and Human Services, 1988). Thus, the neurotransmitter and neuroendocrine effects of nicotine constitute a critical part of its biological action, serving to mediate potential pathophysiological consequences as well as reinforcement.

The present review will concern itself primarily with nicotine's neuroregulatory effects, describing recent research in both laboratory animals and humans. Nicotine's effects on cholinergic and non-cholinergic nicotinic receptors, as well as the responses of catecholamines, monoamines, hypophyseal hormones, and cortisol, will be highlighted. Of necessity, this review will examine findings based on a number of approaches and techniques, with dependent measures

Correspondence to be addressed to: Ovide F. Pomerleau, Ph.D., Behavioral Medicine Program, University of Michigan, Department of Psychiatry, Riverview Medical Building, 900 Wall Street, Ann Arbor MI 48105, USA. 
including iontophoresis, drug discrimination responding, electrocortical activity, autonomic responses, and overt behavior such as nicotine self-administration and free-field activity. For ease of presentation, effects on single neuroregulators will be emphasized, but it is important to note that there are extensive interrelationships among these substances (Meites \& Sonntag, 1981; Tuomisto \& Mănnistö, 1985). Research of the past decade has demonstrated that the relationships between neuroregulators and behavior are remarkably complex (cf., for example, Oades, 1985).

\section{CHOLINERGIC EFFECTS}

\section{Sites of Action}

Despite the large number of experimental studies conducted on the effects of nicotine in the central nervous system, the precise mechanisms involved in behavioral and physiological responses to the drug are by no means fully elucidated (cf. review by Balfour, 1982). Though nicotine has widespread peripheral actions, behavioral effects are primarily due to its central actions. The centrally active nicotine antagonist, mecamylamine, has been shown to block a number of nicotine's effects in animals (for example, reducing nicotine-produced seizures, startle responses, alterations in respiratory rate, Y-maze activity, and heart rate and body temperature changes in mice; Collins et al., 1986) and in humans (for example, reducing psychomotor performance enhancement and satisfaction from smoking, producing dysphoria, and increasing nicotine self-administration; Stolerman et al., 1973; Henningfield et al., 1983; Stolerman, 1986; Pomerleau et al., 1987). In contrast, quarternary blockers such as hexamethonium and chlorisondamine, which do not readily enter the CNS, are ineffective (Stolerman et al., 1973; 1983; Clarke \& Kumar, 1983; Clarke, 1984; Collins et al., 1986).

Nicotine mimics certain actions of the neurotransmitter, acetylcholine. In the peripheral nervous system, it acts on two types of cholinergic receptors: autonomic ganglia receptors, which are antagonized by hexamethonium (C6, denoting the number of carbons between quarternary nitrogens), and neuromuscular junction receptors, where decamethonium (C10) is a selective antagonist (Paton \& Zaimis, 1951). Nicotine functions as an agonist in low doses at these receptors but blocks transmission after initial agonist activity at high doses (Volle \& Koelle, 1975). The evidence for C10 receptors in mammalian brain is equivocal, but most actions of nicotine that occur at behaviorally relevant doses can be blocked by C6-selective antagonists such as mecamylamine (Clarke, 1987). Stereoselective behavioral actions of nicotine have been reported, consistent with receptor mediation (Meltzer et al., 1980; Kumar et al., 1983; Garcha et al., in press). The reinforcing effects of nicotine and tobacco smoking appear to be mediated by C6 receptors in the CNS (Hanson et al., 1979; Tennant et al., 1984; Clarke et al., 1985). By way of explaining nicotine's biphasic effects (i.e., stimulation followed by inhibition of responding, particularly evident at high levels), Marks et al. (1983) and Collins et al. (1986) reviewed evidence supporting the possibility of agonist-induced conformational changes of the nicotine receptor to a desensitized form (Schwartz \& Kellar, 1983), which could account for nicotine's ability to act functionally as an antagonist but mechanistically as an agonist.

Continuing progress is being made in characterizing the nicotinic cholinergic receptor, correlating molecular structure with functional properties (Conti-Tronconi \& Raftery, 1982). This receptor was the first neurotransmitter receptor to be identified as a molecular entity, isolated and purified in an active form, and reconstituted in artificial membrane systems with quantitative retention of physiological properties. Of particular relevance to the understanding of tobacco smoking, recent studies have also demonstrated that nicotine binding sites in the human brain are stable in post-mortem preparations (Benwell \& Balfour, 1985) and that these sites clearly function as nicotinic cholinergic receptors in saturation binding studies (Shimohama et al., 1985). The 
possibility of a "nicotine-like" endogenous ligand has been raised (Sershen et al., 1984), based on the observation that mouse brain homogenates contain material that inhibits saturable binding of 3H-nicotine in mouse cerebral cortex. Finally, the possibility that nicotine also acts on noncholinergic nicotinic receptors in the brain (Abood et al., 1981; Rosecrans \& Meltzer, 1981) continues to be a subject of speculation (Clarke, 1987).

Nicotinic and muscarinic binding sites in brain have different biochemical characteristics and neuroanatomical distributions and are regulated in vivo by different cholinergic agonists (Marks \& Collins, 1985). The functional independence of the two cholinergic systems has been demonstrated in various drug discrimination paradigms (Rosecrans \& Meltzer, 1981). Interactions between the two systems also have been observed. For example, anatomical data suggest that some nicotine receptors in brain have a presynaptic location (Clarke et al., 1986), and there is evidence for nicotinic autoreceptors promoting acetylcholine release in the cerebral cortex (Armitage et al., 1968; Rowell \& Winkler, 1984), and in the autonomic nervous system (Briggs \& Cooper, 1982). Thus, at certain cholinergic synapses, nicotine may act presynaptically to release acetylcholine onto postsynaptic muscarinic cholinoceptors (Chiou et al., 1970). Moreover, Weiler et al. (1984) have shown that presynaptic muscarinic neurons modulate post-synaptic nicotine neurons, at least in the neostriatum. Arrangements between neurons may vary within the cholinergic system; for example, both patterns may exist at hippocampal sites (Bird \& Aghajanian, 1976; Segal, 1978; Rovira et al., 1983).

Thus far, the sites of nicotine action have been discussed without resolving the issue of whether C6 sites are physiological receptors upon which nicotine is acting, or whether they are merely nonspecific neuronal sites to which nicotine attaches itself. Furthermore, the question of whether central receptor entities are similar to those in the periphery should be resolved. Neither issue can be settled satisfactorily at the present time, but, taking the second question first, the fact that mecamylamine is an effective nicotine antagonist at both locations suggests that there must be similarities between CNS nicotine receptors and those in the autonomic ganglia.

With regard to the first question, there is evidence to show that sites bound by ${ }^{3} \mathrm{H}$-nicotine are sensitive to ${ }^{3} \mathrm{H}$-acetylcholine as well (Clarke et al., 1985). There is good correspondence between maps of nicotine and acetylcholine binding, and there is a close association between brain areas of increased cerebral metabolism (2-deoxyglucose) following physiological doses of nicotine (Grunwald et al., 1988; London et al., 1988). Thus, there appears to be a correlation between function and binding. A major difficulty arises, however, in comparing $3 \mathrm{H}$-nicotine and/or ${ }^{3} \mathrm{H}$ acetylcholine maps with 125I- $\alpha$-bungarotoxin (BTX) binding sites (BTX has been used for a long time as a marker for mapping nicotine receptors). This heterogeneity may reflect the activity of two populations of nicotine receptors, each with different binding affinities (Harfstrand et al., 1988). Accordingly, ${ }^{3} \mathrm{H}$-nicotine and ${ }^{3} \mathrm{H}$-acetylcholine may label high affinity binding sites, whereas 125I-BTX most probably labels low affinity sites. The two receptor populations may mediate different effects (Collins et al., 1986; Wonnacott, 1987).

\section{Physiological Effects}

Nicotine's cholinergic effects are extensive. Among the physiological effects of nicotineinduced acetylcholine release (from the parietal cortex in cats) is desynchronization of the cortical electroencephalogram; reduced acetylcholine levels, observed after high doses of nicotine, are associated with decreased cortical activity (Armitage et al., 1968). A similar pattern of changes has been reported for the human electroencephalographic response to cigarette smoke (Remond $e t$ al., 1979). In conscious cats, there is evidence that atropine blocks the cortical activation but not the behavioral arousal seen in animals given intravenous nicotine (Hall, 1970). Accordingly, Balfour (1982) suggested that cortical arousal is mediated by acetylcholine release, but that 
behavioral stimulation is either not mediated by acetylcholine release or does not depend upon the action of acetylcholine at a muscarinic receptor. Nelson et al. (1975) also showed that behavioral suppression induced by electrostimulation of the midbrain reticular formation (MRF) was attenuated by the subcutaneous (SC) administration of $100 \mathrm{mg} / \mathrm{kg}$ of nicotine. These workers suggested that the effect may reflect activation of nicotinic receptors located in the limbic system, and most probably, the hippocampus.

Studies involving intracerebral administration of nicotine have been employed to determine the loci of nicotine's action (e.g., Kamerling et al., 1982; Wu \& Martin, 1983). While some of the effects obtained by the direct application of nicotine to the brain may differ from those produced by systemic administration, the technique is helpful in elucidating nicotine's cholinergic mechanisms of action. The injection of nicotine into the cerebral ventricles of cats, dogs, and rats has been shown to produce a variety of physiological effects, including changes in cardiovascular activity, body temperature, respiration, salivation, muscle reflex tone, and electrocortical indices of sleep and arousal, the direction and duration of effects depending on dose and baseline response parameters (cf. review by Hall, 1982). Concerning the locus of action for the stimulus properties of nicotine, Rosecrans (1988) has shown that nicotine's ability to establish discriminative control of behavior (via subcutaneous administration) is mediated by mecamylamine-sensitive cholinergic neurons located in at least two brain areas, the midbrain reticular formation and the dorsal hippocampus. Interestingly, the effects generated at hippocampal neurons were stereoselective, and (t)-nicotine was approximately 10 times less active than the (-)-isomer in generalization tests.

Complex dose-related behavioral effects also have been observed following the systemic administration of nicotine (Clarke, 1987), including changes in locomotor activity, operant responding and conditioned avoidance, nociception, aggression, and food and water intake. Of particular relevance to the understanding of reinforcement of smoking are reports from both animal and human studies of improvements in task performance, stimulus discrimination, learning, and memory, as well as reduction of fear and anxiety and modulation of arousal (cf. review by Pomerleau \& Pomerleau, 1984).

Understanding nicotine's effects on neuroregulatory systems will require the ability to differentiate between neuroregulatory effects and mechanisms of action at specific cholinergic neurons, for many of nicotine's consequences are secondary to its cholinergic effects. The timetested approach has been to use nicotinic ( $\mathrm{N}$-cholinergic) and muscarinic (M-cholinergic) antagonists. As initially demonstrated by Domino (1973) in the cat and more recently by Stolerman et al. (1983) and Rosecrans (1988) in the context of studying the discriminative stimulus properties of nicotine in the rat, mecamylamine is the most effective antagonist of nicotine, both in vivo and in vitro. The peripheral ganglionic blocker, hexamethonium, and the muscarinic antagonists, atropine and scopolamine, are less effective as nicotine antagonists. Nicotine acts on a select group of receptors centrally, and receptor interactions appear to be quite specific, resembling those of few other compounds. The exceptions are alkaloidal analogs such as cytisine and anabasine and the chemical stereo-isomers, 3-methyl-pyrridyl-pyrolidine and ( $t)$ nicotine (Rosecrans \& Meltzer, 1981; Stolerman et al., 1983; Abood et al., in press). Thus, nicotine and its analogs appear to constitute a class distinct from other psychopharmacological agents, and the comparison with other psychoactive drugs is not straightforward.

As the above discussion indicates, nicotinic cholinergic events are only the first step in nicotine's neuroregulatory effects on the nervous system. This is underscored by a study by Rosecrans (1987), using the drug discrimination procedure, which demonstrated that intact central dopamine (DA) function may be required to elicit the discriminative stimulus (DS) properties of nicotine injected into the hippocampus. Adding further support, a number of studies have demonstrated cholinergic modulation of central catecholamine activity by nicotine (e.g., 
Andersson, 1985). Though there is still disagreement about the precise mechanisms, nicotine has been shown to stimulate norepinephrine (NE) release in the hypothalamus by a calcium-dependent process that can be inhibited by prior administration of hexamethonium or acetylcholine (Hall \& Turner, 1972; Westfall, 1974). The mechanism is similar to that of nicotine's effects on peripheral adrenergic nerve terminals (Westfall \& Brasted, 1972). At high dose levels, nicotine stimulates norepinephrine (NE) release by displacing it from vesicle stores at sites outside the hypothalamus (Balfour, 1982). Of considerable interest for the understanding of nicotine's sympathomimetic properties and the enhancement of attention and arousal following smoking (Svensson, 1987) is the demonstration of a direct action of nicotine on the rat locus coeruleus via nicotinic cholinergic receptors (Egan \& North, 1986).

\section{MODULATION OF SEROTONIN AND CATECHOLAMINE ACTIVITY}

\section{Interrelationships with acetylcholine pathways}

The anatomical localization and physiological/psychological importance of biogenic amines such as serotonin (5-HT), DA, and NE has been the subject of intense research over the last 30 years. It was not until 1966, however, that the classic studies of Dahlstrom and Fuxe (1966) revealed that these amine-containing neurons were localized in specific ascending projection systems; descending systems have also been described. The physiological integrity of these systems was further demonstrated by the investigations of Aghajanian et al. (1967) in which the stimulation of 5-HT cell bodies localized in the midbrain raphe nucleus elicited the release of this transmitter from nerve endings located in the more rostral forebrain. The recognition that these amine systems constitute a unique interneuronal communication system has played a central role in the understanding of underlying neurochemical mechanisms of behavior and has made possible improved strategies for treating specific psychiatric and neurological disorders.

The cholinergic system has undergone a similar analysis (Fibiger, 1982). Delineating specific cholinergic pathways has been more difficult because of the nature of the cholinergic system, but they do appear to have a similar organization and to interact with specific biogenic amine pathways. For example, Robinson (1983) has clearly shown that 5-HT and DA systems exert tonic control over acetylcholine tumover in both the hippocampus and frontal cortex: Lesions of the medial raphe nuclei increase the acetylcholine turnover rate in hippocampal sites, while lesions of the dorsal raphe elicit a similar effect in frontal cortical areas; evidence for DA control comes from the observation that the catecholamine neurotoxin, 6-OHDA, facilitated hippocampal acetylcholine turnover when injected into the DA-rich septal area. The research of Kellar et al. (1987) and others also suggests that some nicotinic receptors may inhabit a presynaptic site on certain DA and 5-HT nerve endings. In addition, Westfall et al. (1983) have shown that 1,1dimethyl-4-phenyl-piperazinum iodide (DMPP)-induced stimulation of nicotinic receptors in the striatum facilitates the release of both 5-HT and DA in a tissue slice preparation; of importance is that this preparation is devoid of cell bodies, suggesting that these nicotinic cholinergic receptors are primarily presynaptic. Furthermore, hexamethonium, but not atropine, attenuated nicotineinduced amine release, indicating that these neurons are nicotinic rather than muscarinic in nature.

Thus, when discussing nicotine's effects on specific biogenic amine-containing neurons, one must bear in mind that these amine systems have many interconnections and that, even though a specific receptor may be stimulated, either activation or inhibition of a particular 5-HT, NE, or DA neuron may be the ultimate outcome. Conversely, the integrity of specific nicotinic cholinergic neurons may also be under the control of one of these biogenic amine-containing projection systems. Nicotine, for example, appears to produce its discriminative stimulus effect in at least one major brain area, the hippocampus. This site is rendered insensitive if DA neurons 
innervating this area are destroyed (Rosecrans, 1987). Therefore, the interrelationships of these amine pathways are extremely important to our understanding of nicotine's effects on behavior, and especially its effects on the neuroendocrine system, because of the central role that these amine systems play in the hypothalamic control of the pituitary.

\section{Effects on serotonergic neurons}

Research evaluating the relationship between nicotine and 5-HT has involved several different approaches. Hendry \& Rosecrans (1982) compared the behavioral effects of nicotine in rats selected for differences in activity and 5-HT tumover. The hypothesis was that, depending upon the rate of 5-HT tumover, nicotine would alter behavior by either attenuating or augmenting the level of functioning of 5-HT neurons having inhibitory effects on behavior. A variety of different strategies have been adopted to test this hypothesis, but conclusive evidence that nicotine acts via some 5-HT mechanism has yet to be obtained. Despite the failure to demonstrate a relationship between behavior and nicotine-modulated 5-HT function, however, Balfour et al. (1975) observed that acute doses of nicotine were capable of attenuating hippocampal 5-HT turnover, an effect specific to the hippocampus. Fuxe et al. (1987), on the other hand, did not observe any acute changes in 5-HT function following acute nicotine dosing but did observe a significant reduction of 5-HT tumover following repeated doses $(3 \times 2 \mathrm{mg} / \mathrm{kg}$ every $\mathrm{hr})$; however, this effect may have been due to the metabolism of nicotine to cotinine, since the reduction of 5-HT turnover was not attenuated by mecamylamine.

5-HT function correlates with some pharmacological effects of nicotine, and investigators have evaluated potential links between 5-HT and neuroendocrine function. Balfour et al. (1975) were among the first to show a relationship between 5-HT and nicotine's ability to induce the release of plasma corticosterone, presumably via activation of the pituitary-adrenal axis. Basic findings from ensuing research were that (1) a reduction in 5-HT tumover (correlated with an increase in plasma corticosterone) followed acute nicotine injections in the rat; (2) rats exhibited tolerance to pituitar -activation following repeated nicotine doses, but not to the attenuation of hippocampal 5-HT turnover; (3) psychological stress antagonized nicotine-induced reductions of hippocampal 5-HT; and (4) nicotine inhibited the normal adaptive response to adrenocortical stimulation following chronic stress (Balfour et al., 1986). These data suggest that nicotine can modify the way in which rats adapt to stress, which may be mediated by changes in hippocampal 5-HT function. At this point, however, it is difficult to draw any firm conclusions concerning how nicotine affects 5-HT neurons and whether this neurotransmitter is uniquely involved in any of nicotine's effects on neuroendocrine function. The fact that hippocampal 5-HT turnover appears to be selectively attenuated by nicotine, combined with the fact that this brain area has a high concentration of nicotinic cholinergic receptors, is nonetheless an important finding that should be further studied and evaluated.

\section{Effects on noradrenergic and dopaminergic neurons}

Attempts to determine whether nicotine produces any effects on NE-containing neurons have met with mixed success. Earlier work suggested that nicotine may affect behavior via an NE component, but subsequent research was not supportive of such claims (Balfour, 1982). Svensson (in press) provided evidence that NE neurons located in the locus coeruleus are activated by nicotine centrally, resulting in sympathetic activation. The ability of nicotine to alter DA function has been the subject of numerous investigations. As outlined above, investigators have observed that nicotine is capable of releasing DA from brain tissue (Westfall et al., 1983). Lichtensteiger $e t$ al. (1982) also observed nicotine to release DA through an acceleration of the firing rate of DA cell bodies located in the substantia nigra zona compacta when administered via iontophoretic application or $\mathrm{SC}(0.4-1.0 \mathrm{mg} / \mathrm{kg})$. This activation was marked by a significant increase in striatal 
DA turnover; dihydro- $\beta$-erythroidine, but not atropine, attenuated nigrostriatal activation. Evidence that nicotine facilitates the firing of DA cell bodies by stimulating nicotinic cholinergic receptors has been strengthened by the work of Clarke et al. (1985), who showed a specific effect by nicotine on pars compacta cell bodies, which was antagonized by mecamylamine. In an investigation of the release of DA from synaptosomes, Connelly and Littleton (1983) noted that DA release lacked stereoselectivity but was antagonized by the ganglionic blocker, pempidine. Imperato et al. (1986) showed that these effects occurred in the freely moving rat as well as in vitro. In these studies, nicotine specifically released DA from the nucleus accumbens, as opposed to the caudate nucleus.

Other studies provide further information that nicotine can greatly influence DA function, as do several other drugs of abuse (Westfall et al., 1983; Mereu et al., 1987). Studies involving either peripheral or intracranial injection into DA-rich areas - namely the substantia nigra pars compacta (A9) and the ventral tegmental area (A10) - indicate that nicotine can greatly facilitate firing rates of these neuronal sites, an effect antagonized by mecamylamine. Westfall et al. (1983) and Mereu et al. (1987) suggested that the nicotine-induced stimulation of striatal and nucleus accumbens neurons (via the facilitation of A9 and A10 firing rates) was related to the removal of tonic inhibitory influences from adjacent non-DA neurons, i.e., GABA-inhibitory neurons. Thus, these relationships are quite complicated and appear to be related to interactions at several interneuronal connections, monoaminergic as well other amino acid systems.

A DA reward theory of drug reinforcement, based on observations of psychomotor activation common to a number of substances of abuse involving activation of DA pathways (medial forebrain bundle projections to limbic and cortical regions), has been proposed (Wise \& Bozarth, 1987; Wise, 1988). The inclusion of nicotine is supported by the demonstration of nicotine stimulation of ventral tegmental DA neuronal activity (Svensson et al., 1986), consistent with evidence of nicotinic receptors on DA neurons (Clark \& Pert, 1985). The implications of this theory for understanding nicotine's mechanisms of action are not worked out. Finally, from an entirely different perspective, Janson et al. (1988) proposed that nicotine may protect DA neurons from neurotoxic destruction under certain conditions, for example, retarding the development of Parkinson's disease or delimiting damage from the DA toxin MPTP (1-methyl-4-phenyl-2,3,6tetrahydropyridine). The process may be the result of attenuation of DA neostriatal neuronal activity via desensitization of nicotinic receptors controlling DA turnover. How these observations fit into what is known about nicotine modulation of DA function is not clear, though it should be noted that most of the above studies were conducted with acute nicotine dosing and that different results might be obtained with repeated, chronic dosing. It is possible that nicotine may be acting as an antagonist of DA systems in the regular smoker by producing a chronic desensitization of DA receptors.

Fuxe and coworkers (Fuxe et al., 1986) have long been interested in nicotine's effects on central catecholamine neurons in relation to neuroendocrine function. Their measurements of amine function utilize quantitative histofluorometric techniques rather than the more classical neurochemical and neuropharmacological methods. The procedure involves measuring the disappearance of catecholamine stores by administering a tyrosine hydroxylase inhibitor (AMPT) to rats receiving various doses of nicotine or exposed to tobacco smoke; tissues are then exposed to formaldehyde gas, and histofluorescence in AMPT-treated rats is evaluated in comparison to controls. This procedure has served these workers well over the years and has provided important information concerning nicotine's effects on biogenic amine function.

Their findings clearly indicate that nicotine is a potent activator of both DA and NE neuron systems located primarily in the median eminence and in areas of the hypothalamus. These effects appear to result from a stimulation of nicotinic cholinergic receptors generally antagonized 
by mecamylamine. Concomitant neuroendocrine changes include reduction of plasma prolactin, thyroid-stimulating hormone, and luteinizing hormone, and an increase in corticosterone, following intermittent nicotine dosing $(4 \times 2 \mathrm{mg} / \mathrm{kg}, S C$ every $30 \mathrm{~min}$ ) or tobacco smoke exposure (rats were exposed from one to four cigarettes containing $2.6 \mathrm{mg}$ and received eight puffs at 10 min intervals). It should be noted that nicotine doses of $0.3 \mathrm{mg} / \mathrm{kg}$ administered intravenously will induce an overall activation of the hypothalamic-pituitary axis, leading within minutes to an increase of both ACTH and prolactin that subsides within $60 \mathrm{~min}$. Tolerance to the corticosterone increase was observed following repeated nicotine doses, but there was little evidence for an effect of nicotine on either the increase in DA or the decreases in prolactin, luteinizing hormone, and follicle-stimulating hormone. Restraint stress also was observed to increase ACTH, corticosterone, and prolactin and to reduce DA and NE levels in hypothalamic regions. Interestingly, this stressor attenuated nicotine's activation of NE neurons but did not reverse its attenuating effects on prolactin.

From these studies, Fuxe and colleagues' conclusion is that nicotine appears to modulate neuroendocrine activity via either NE or DA activation. The evidence suggests that alterations in NE function are more important to the control of the pituitary-adrenalaxis, while DA turnover appears to be more crucial to nicotine's effects on prolactin, luteinizing hormone, and folliclestimulating hormone. An important implication of this research is that nicotine-induced effects do not appear to be merely a reflection of acute and/or chronic stress but are rather quite specific, involving nicotinic cholinergic receptors that are probably located on a presynaptic DA or NE neuronal site. These studies further indicate that similar nicotinic cholinergic receptors are located within both DA mesolimbic and DA neostriatal systems (Fuxe et al., 1987).

\section{STIMULATION OF PITUITARY HORMONES}

The administration of nicotine can modify the release of both neurohypophyseal (posterior pituitary) and adenohypophyseal (anterior pituitary) hormones (Bisset et al., 1975; Hall et al., 1978). Among the pituitary hormones whose levels are modulated by nicotine are arginine vasopressin (antidiuretic hormone) and its carrier protein, neurophysin $I$, as well as growth hormone, prolactin, ACTH, and $\beta$-endorphin $\beta$-lipotropin. Each of these substances has complex physiological effects (Munck et al., 1984), and several have psychoactive effects (Kastin $e t$ al., 1979; van Ree \& de Wied, 1981). Nicotine's effects on these and related hormones will be reviewed next.

\section{Arginine vasopressin}

Arginine vasopressin, in addition to its antidiuretic effects (maintaining plasma volume in hemormagic shock; Munck et al., 1984), serves as potent general vasoconstrictor with a possible action on the coronary arteries (Waeber et al., 1984). Arginine vasopressin may also act as a neuromodulator in pathways that affect behavior. It has been shown to promote memory consolidation and retrieval in rats (Bohus et al., 1978), and though the findings are far from definitive, there are reports of memory enhancement following intranasal administration of a vasopressin analogue in both normal and memory-deficient humans (Le Boeuf et al., 1978; Legros et al., 1978; Weingartner et al., 1981). A nicotinic cholinergic receptor in the medial basal hypothalamus and a muscarinic cholinergic receptor in the neurohypophysis have been shown to mediate the cholinergic release of vasopressin (Gregg, 1985). Nicotine has been found to stimulate vasopressin release in a dose-related manner in both animals (Reaves et al., 1981; Siegel et al., 1983) and humans (Pomerleau et al., 1983; Dietz et al., 1984; Seyler et al., 1986). 
The pro-opiomelanocortin (POMC) group of hormones

The POMC hormones have been shown to be released in response to stress [more precisely, in response to the homeostatic perturbations caused in large part by the primary (i.e., catecholamine) response to stress; Munck et al., 1984], as well as to corticotropin-releasing hormone (Krieger \& Martin, 1981). One of the POMC hormones, ACTH, has a number of behavioral effects in addition to its physiological role in stimulating the release of steroids such as cortisol from the adrenal cortex. A provocative review by Bertolini and Gessa (1981) describes the "stretchingyawning syndrome" in animals, in which ACTH produces rapid cycling between sleep and wakefulness as well as sexual stimulation, grooming/scratching, blocking of opiate effects such as analgesia, and the enhancement of attention and stimulus discrimination. Similarly, endogenous opioids such as $\beta$-endorphin, in addition to having physiological functions such as potentiation of vagal reflexes, promotion of respiratory depression, lowering of blood pressure, and blocking of the release of catecholamines (Beaumont \& Hughes, 1979; Schwartz, 1981), have powerful antinociceptive effects (van Ree \& de Wied, 1981) and modulate neurotransmitter systems, leading to amnesic effects (Izquierdo et al., 1980; Introini \& Baratti, 1984). Margules (1979) speculated that the primary function of the endogenous opioids is metabolic, conserving body resources and energy (cf. reviews by Amir et al., 1980; Millan \& Emrich, 1981).

Nicotine stimulates the release of corticotropin-releasing hormone from the hypothalamus through a nicotinic cholinergic pathway (Hillhouse et al., 1975; Weidenfeld et al., 1983). Using an isolated perfused mouse brain preparation, Marty et al. (1985) demonstrated that nicotine stimulates secretion of $\beta$-endorphin and ACTH in a dose-related manner when applied directly to the hypothalamus, but not when applied to the pituitary. Nicotine administration also has been shown to increase the levels of plasma corticosterone, ACTH, and $\beta$-endorphin in a dose-related manner in rats (Conte-Devolx et al., 1981). Termination of chronic nicotine administration has been shown to reduce hypothalamic $\beta$-endorphin levels (Rosecrans et al., 1985). Corrigall et al. (1988) observed that naltrexone antagonizes nicotine-modulated behavior in mice, providing a link between nicotine stimulation of endogenous opioid activity and behavioral responses. Acute administration of nicotine has been shown to increase levels of plasma ACTH and corticosterone sharply (Cam \& Bassett, 1983), while chronic exposure results in complete adaptation (Cam \& Bassett, 1984).

Freund et al. (1988) observed that mouse strains vary greatly in their corticosteroid response to acute and chronic nicotine administration. Pauly et al. (1988) extended this research on corticosteroid modulation of physiological and behavioral sensitivity to nicotine: Nicotine cholinergic receptor number was unaffected and nicotine metabolism was unchanged by adrenalectomy in mice, but sensitivity to the effects of nicotine was greatly enhanced. These changes could have been due to lack of adrenocortical hormones or to increases in brain concentration of ACTH and/or CRF as a result of loss of corticosteroid feedback inhibition (McEwen et al., 1986), but administration of corticosterone restored protection to nicotine in adrenalized mice (i.e., it brought sensitivity to nicotine back to the levels of sham-operated animals).

In humans, Risch et al. $(1980 ; 1982)$ accumulated evidence for the cholinergic control of cortisol, prolactin, and $\beta$-endorphin release. Consistent with these findings, Pomerleau et al. (1983) and Seyler et al. (1984), in a series of studies on cigarette smokers, demonstrated significant, dose-related increases in circulating cortisol and $\beta$-endorphin following the smoking of two high-nicotine cigarettes after overnight deprivation; significant ACTH increases, however, occurred only with the nausea associated with very high plasma nicotine levels (Seyler $e t$ al., 1984). Under similar conditions, and in the absence of nausea, nearly identical plasma levels of ACTH, cortisol, and $\beta$-endorphin were observed by Novack and Allen-Rowlands (1985) in 
response to smoking high-nicotine cigarettes.

With respect to other hypophyseal hormones, nicotine has been shown to inhibit the release of thyroid-stimulating hormone, prolactin, luteinizing hormone, and follicle-stimulating hormone in rats (Muraki et al., 1979; Andersson, 1985) and to enhance growth hormone secretion (Mendelson et al., 1981). In humans, smoking-induced stimulation of growth hormone and prolactin were reported by Wilkins et al. (1982); though no nausea was observed, fairly high plasma nicotine levels were achieved. Seyler et al. (1986) attempted to characterize the hypophyseal response pattem to cigarette smoking: After subjects smoked two high-nicotine cigarettes in such a way as to reach satiation (defined by the onset of nausea), significant elevations were found for prolactin, ACTH, $\beta$-endorphin/ $\beta$-lipotropin, growth hormone, arginine vasopressin, and neurophysin I, in the absence of changes in the levels of thyroid-stimulating hormone, luteinizing hormone, or follicle-stimulating hormone. At somewhat lower doses and in the absence of nausea, the pattern of release was more selective, with significant elevations in arginine vasopressin, neurophysin I, and $\beta$-endorphin $\beta$-lipotropin only; after two low-nicotine cigarettes, no observable changes in the circulating levels of the hormones occurred.

There is a need for further investigation of the factors controlling individual variability in the release of nicotine-stimulated hypothalamic and hypophyseal hormones associated with dysphoric states such as nausea (Seyler et al., 1986); such studies may shed light on the mechanisms by which nicotine intake is regulated and smoking behavior is reinforced (Kozlowski, 1980). It also should be noted that the onset of nausea following the first smoking experience may be an important factor in determining why some people take up smoking and others do not (Kozlowski \& Harford, 1976). Susceptibility to nausea induced by nicotine or by other substances that stimulate the emetic center may provide an index of receptivity to smoking, and associated hormonal patterns may constitute an objective indicator of subjective effects.

The functional significance of nicotine-induced hormonal patterns and the role of neuroregulators in smoking is poorly understood. While there is an extensive literature on the use of agonists and antagonists to demonstrate relationships between cholinergic activity and particular behavioral effects (Henningfield et al., 1983; Kumar et al., 1987), and while similar strategies have been employed in the exploration of catecholaminergic contributions to smokingrelated behavior, as reviewed above, the exploration of the contribution of neuroregulators to the reinforcement of smoking behavior is still at a very primitive stage.

For example, concerning the role of nicotine-stimulated endogenous opioid activity, Karras and Kane (1980) found that administration of the opioid antagonist, naloxone, resulted in a significant reduction in smoking behavior in a work setting; these findings have been replicated in a laboratory setting by Gorelick et al. (1989). Similarly, in a preliminary study, Palmer and Berens (1983) reported that naloxone blocked subjective pleasure from smoking. In a study that examined the role of endogenous opioid mechanisms in smoking, Tobin et al. (1982) had observed that mean inspiratory flow rate increases during the smoking of a cigarette but is depressed shortly after smoking; they administered naloxone and found that it had no effect on the initial stimulation of respiration in response to smoking but did significantly blunt the subsequent depression of respiration. On the other hand, in a carefully-designed parametric study in which naloxone dosage was varied systematically, Nemeth-Coslett and Griffiths (1986) were unable to demonstrate any systematic effect of naloxone on subsequent smoking behavior. The exact contribution of the endogenous opioids to smoking remains to be determined.

\section{IMPLICATIONS FOR UNDERSTANDING TOBACCO USE AS AN ADDICTION}

It is important to point out that nicotine's neuroregulatory effects are not fixed and invariant 
but are dynamic, the product of interactions among environmental conditions, history of nicotine use, and behavior. Thus, under certain conditions, nicotine administration serves as a reinforcer, but under other conditions, nicotine can be used to punish self-administration (Barrett, 1983; Henningfield \& Goldberg, 1983). As reviewed at some length by Benowitz (1988) and by Russell (1988), mode of administration is important in determining the effects that nicotine will have on behavior, with modalities like nicotine chewing gum or the transdermal patch producing slow nicotine rise-times, which foster tolerance, and other modalities such as cigarette smoking and aerosols producing a sharp rise in plasma nicotine, thereby overcoming tolerance. Specifically, nicotine's biphasic pattern, in which the enhancement of arousal and alertness is followed by calming and tension-reduction, can be modified by changes in self-dosing (Gilbert, 1979; Pomerleau \& Pomerleau, 1984), thereby achieving selective emphasis of one component or the other under the apparent control of demands of the setting (Warburton \& Wesnes, 1979; Golding \& Mangan, 1982; Rose et al., 1983) and/or personality characteristics (Myrsten et al., 1975). The neuroregulatory implications of these phenomena are not well understood. Nicotine's biphasic effect on behavioral arousal has been known for some time; for example, Silvette et al. (1962) noted that lower doses of nicotine (200 to $400 \mu \mathrm{g} / \mathrm{kg}$ ) stimulated spontaneous activity in rats, whereas higher doses $(800 \mu \mathrm{g} / \mathrm{kg})$ depressed this behavior. Rosecrans (1971) demonstrated that a $400 \mu \mathrm{g} / \mathrm{kg}$ dose produced maximal modulation, with acute doses stimulating more spontaneous activity in low activity rats than in high activity rats; nicotine-induced elevation of arousal level was directly related to inhibition of 5-HT turnover, suggesting that nicotine's variable effects on the behavior of animals of different temperaments might be related to its effects on the forebrain serotonin projection system.

A biobehavioral analysis has been proposed to provide a framework for categorizing and evaluating the diverse findings on nicotine and smoking, as well as for guiding experimentation (Pomerleau \& Pomerleau, 1984). The key elements of smoking - susceptibility, setting, behavior, and reinforcement - have been evaluated in terms of putative neuroregulatory components, highlighting the interactions between external environment and biological substrate in the control of nicotine self-administration and smoking (Pomerleau \& Pomerleau, 1989). A fundamental premise is that by altering the bioavailability of certain behaviorally-active neuroregulators, nicotine serves as a pharmacological "coping response", promoting immediate, temporary improvements in affect or performance (at the likely cost of delayed pathophysiological consequences).

Knowledge about the neuroregulatory mechanisms by which nicotine exerts its rewarding and health-damaging effects is incomplete and sketchy. For instance, the contribution of critical variables such as the timing and duration of release and patterns in nicotine's neuroendocrine response, taking into account different environmental demands, history of nicotine use, and mode of administration, is still largely unknown. Much of what is known has been based on the administration of agonists and antagonists under different environmental conditions. Newer technological approaches such as autoradiography and positron emission tomography (Maziere $e t$ al., 1979; London et al., 1985; Kuhar et al., 1986) show potential for determining the neuroregulatory patterns involved and for specifying nicotine's locus of action relevant to its behavioral and physiological effects.

Acknowledgements: Supported in part by National Cancer Institute grant CADA 42730 to Ovide F. Pomerleau and National Institute on Drug Abuse grant DA 04002 to John Rosecrans. 


\section{REFERENCES}

Abood LG, Reynolds DT, Booth H, Bidlack JM (1981) Sites and mechanisms of nicotine's actions in the brain. Neurosci Biobehav Rev 5: 479-486.

Abood LG, Banerjee S, Kanne DB (1989) Sites, mechanisms, and structural characteristics of the brain's nicotine receptor. J Subst Abuse 1: 259-272.

Aghajanian GK, Rosecrans JA, Sheard MH (1967) Serotonin release in the forebrain by stimulation of the midbrain raphe. Science 15: 402-404.

Amir S, Brown ZW, Amit Z (1980) The role of endorphins in stress: evidence and speculations. Neurosci Biobehav Rev 4: 77-86.

Andersson K (1985) Mecamylamine pretreatment counteracts cigarette smoke induced changes in hypothalamic catecholamine neuron systems and in anterior pituitary function. Acta Physiol Scand 125: 445-452.

Armitage AK, Hall GH, Morrison CF (1968) Pharmacological basis for the smoking habit. Nature 217: 331-334.

Balfour DJK (1982) The effects of nicotine on brain neurotransmitter systems. Pharmacol Ther 16: 269-282.

Balfour DJK, Khuller AK, Longden A (1975) The effects of nicotine on plasma corticosterone and brain amines in stressed and unstressed rats. Pharmacol Biochem Behav 3: 179-184.

Balfour DJK, Graham CA, Vale AL (1986) Studies on the possible role of brain 5-HT systems and adrenocortical activity in behavioural responses to nicotine and diazepam in an elevated x-maze. Psychopharmacology 90: 528-532.

Barrett JE (1983) Interrelationships between behavior and pharmacology as factors determining the effects of nicotine. Pharmacol Biochem Behav 19: 1027-1029.

Beaumont A. Hughes J (1979) Biology of opioid peptides. Annu Rev Pharmacol Toxicol 19: 245-267.

Benowitz NL (1988) Toxicity of nicotine: implications with regard to nicotine replacement theory. In: Pomerleau OF, Pomerteau CS (Eds) Nicotine Replacement: A Critical Evaluation. Alan R. Liss, New York, pp 187-287.

Benwell MEM, Balfour DJK (1985) Central nicotine binding sites: a study of post-mortem stability. Neuropharmacology 24: 1135-1137.

Bertolini A, Gessa GL (1981) Behavioral effects of ACTH and MSH peptides. J Endocrinol Invest 4: 241-251.

Bird SJ, Aghajanian GK (1976) The cholinergic pharmacology of hippocampal pyramidal cells: a microiontophoretic study. Neuropharmacology 15: 273-282.

Bisset GW, Feldberg W, Guertzstein PG, Rocha E Silva M (1975) Vasopressin release by nicotine: the site of action. BrJ Pharmacol 54: 463-474.

Bohus B, Kovacs GL, de Wied D (1978) Oxytocin, vasopressin, and memory: opposite effects on consolidation and retrieval processes. Brain Res 157: 414-417.

Briggs CA, Cooper JR (1982) Cholinergic modulation of the release of ${ }^{3} \mathrm{H}$-acetylcholine from synaptosomes of the myenteric plexus. J Neurochem 38: 501-508.

Cam GR, Basset JR (1983) The plasma levels of ACTH following exposure to stress or nicotine. Arch Int Pharmacodyn Ther 264: 154-167.

Cam GR, Basset JR (1984) Effect of prolonged exposure to nicotine and stress on the pituitary-adrenocortical response; the possibility of cross-adaptation. Pharmacol Biochem Behav 20: 221-226.

Chiou CY, Long JP, Potrepka R, Spratt JL (1970) The ability of various nicotinic agents to release acetylcholine from synaptic vesicles. Arch Int Pharmacodyn Ther 187: 88-96.

Clarke PBS (1984) Chronic central nicotine blockade after a single administration of the biquaternary ganglionblocking drug chlorisondamine. Br J Pharmacol 83: 527-535.

Clarke PBS (1987) Nicotine and smoking: a perspective from animal studies. Psychopharmacology 92: 135-143.

Clarke PBS, Kumar R (1983) Characterization of the locomotor stimulant action of nicotine in tolerant rats. Br J Pharmacol 80: 587-594.

Clarke PBS, Pert A (1985) Autoradiographic evidence for nicotine receptors on nigrostriatal and mesolimbic dopaminergic neurons. Brain Res 348: 355-358.

Clarke PBS, Schwartz RD, Paul SM, Pert CB, Pert A (1985) Nicotinic binding in rat brain: autoradiographic comparison of ${ }^{3} \mathrm{H}$-acetylcholine, ${ }^{3} \mathrm{H}$-nicotine and ${ }^{125} \mathrm{I}$-alpha-bungarotoxin. $J$ Neurosci 5: $1307-1315$.

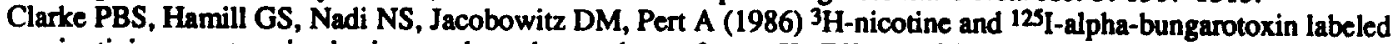
nicotinic receptors in the interpeduncular nucleus of rats. Il. Effects of habenular deafferentation. J Comp Neurol 251: 407-413.

Collins AC, Evans CB, Miner LL, Marks MJ (1986) Mecamylamine blockade of nicotine responses: evidence for two brain nicotinic receptors. Pharmacol Biochem Behav 24: 1767-1773.

Connelly MS, Littleton JM (1983) Lack of stereoselectivity in ability of nicotine to release dopamine from rat synaptosomal preparations. J Neurochem 41: 1297-1302.

Conte-Devolx B, Oliver C, Giraud P, Guillioz P, Castanas E, Lissistzky JC, Boudou-Resque F, Millet Y (1981) Effect of nicotine on in vivo secretion of melanocorticotropic hormones in the rat. Life Sci 28: 1067-1073. 
Conti-Tronconi BM, Raftery MA (1982) The nicotinic cholinergic receptor: correlation of molecular structure with functional properties. Ann Rev Biochem 51: 491-530.

Corrigall WA, Herling S, Coen KM (1988) Evidence for opioid mechanisms in the behavioral effects of nicotine. Psychopharmacology 96: 29-35.

Dahlstrom A, Fuxe K (1966) Evidence for the existence of monoamine-containing neurons in the central nervous system. I. Demonstration of monoamines in the cell bodies on brain stem neurons. Acta Physiol Scand 62 (Suppl 132): 1-55.

Dietz R, Schomig A, Kusterer K, Dart AM, Kubler W (1984) Vasopressor systems during smoking in humans. Klin Wochenschr 62 (Suppl II): 11-17.

Domino EF (1973) Neuropsychopharmacology of nicotine and tobacco smoking. In: Dunn WL (Ed) Smoking Behavior: Motives and Incentives. VH Winston \& Sons, Washington DC, Pp S-31.

Egan TM, North RA (1986) Actions of acetylcholine and nicotine on rat locus coeruleus neurons in vitro. Neuroscience 19: 565-571.

Fibiger HC (1982) The organization and some projections of cholinergic neurons of the mammalian forebrain. Brain Res Rev 4: 327-388.

Freund RK, Martin BJ, Jungschaffer DA, Ullman EA, Collins AC (1988) Genetic differences in plasma corticosterone levels in response to nicotine injection. Pharmacol Biochem Behav 30: 1059-1064.

Fuxe K, Andersson K, Harfstrand A, Agnati LF (1986) Increases in dopamine utilization in certain limbic dopamine terminal populations after a short period of intermittent exposure of male rats to cigarette smoke. J Neural Transm 67: 12-29.

Fuxe K, Andersson K, Eneroth P, Harfstrand A, Nondberg A, Agnati LF (1987) Effects of nicotine and smoking on discrete dopamine and nor-adrenaline nerve terminal systems of the tel-and diencephalon of the rat. Relationship to reward mechanisms and neuroendocrine functions. In: Martin WR, Van Loon GR, Iwamoto ET, Davis LT (Eds) Tobacco Smoking and Nicotine: A Neurobiological Approach. Plenum Press, New York, pp 225-262.

Garcha HS, Goldberg SR, Reavill C, Risner ME, Stolerman IP (in press) Behavioral effects of the optical isomers of nicotine and normicotine, and of cotinine, in rats. Br J Pharmacol (Suppl).

Gilbert DG (1979) Paradoxical tranquilizing and emotion-reducing effects of nicotine. Psychol Bull 86: 643-661.

Golding J, Mangan GL (1982) Arousing and de-arousing effects of cigarette smoking under conditions of stress and mild sensory isolation. Psychophysiology 19: 449-456.

Gorelick DA, Rose JE, Jarvik ME (1989) Effect of naloxone on cigarette smoking. J Subst Abuse 1: 153-159.

Gregg CM (1985) The compartmentalized hypothalamo-neurohypophyseal system: evidence for a neurohypophyseal action of acetylcholine on vasopressin release. Neuroendocrinology 40: 423-429.

Grunwald F, Schrock H, Theilen H, Biber A, Kuschinsky W (1988) Local cerebral glucose utilization of the awake rat during chronic administration of nicotine. Brain Res 456: 350-356.

Hall GH (1970) Effects of nicotine and tobacco smoke on the electrical activity of the cerebral cortex and olfactory bulb. Br J Phamacol 38: 271-286.

Hall GH (1982) Pharmacological responses to the intracerebral administration of nicotine. Pharmacol Ther 15: 223-238.

Hall GH, Turner DM (1972) Effects of nicotine on the release of ${ }^{3} \mathrm{H}$-noradrenaline from the hypothalamus. Biochem Pharmacol 21: 1829-1838.

Hall GH, Francis RL, Morrison CF (1978) Nicotine dependence, avoidance behavior and pituitary-adrenocortical function. In: Battig K (Ed) Behavioral Effects of Nicotine. Karger, Basel, pp 94-107.

Hanson HM, Ivester CA, Morton BR (1979) Nicotine self-administration in rats. Nat Inst Drug Abuse Res Monogr 23: 70-90.

Harfstrand A, Adem A, Fuxe K, Agnati L, Andersson K, Nondberg A (1988) Distribution of nicotinic cholinergic receptors in rat tel- and diencephalon: a quantitative receptor autoradiographical study using [ ${ }^{3} \mathrm{H}$ ]-acetylcholine, [alpha-125]bungarotoxin and [3H]-nicotine. Acta Physiol Scand 132: 1-14.

Hendry JS, Rosecrans JA (1982) Effects of nicotine on conditioned and unconditioned behavior in experimental animals. Pharmacol Ther 17: 431-454.

Henningfield JE, Goldberg SR (1983) Control of behavior by intravenous nicotine injections in human subjects. Pharmacol Biochem Behav 19: 1021-1026.

Henningfield JE, Miyasoto K, Johnson RE, Jasinski DR (1983) Rapid physiologic effects of nicotine in humans and selective blockade of behavioral effects by mecamylamine. In: Harris LS (Ed) Problems of Drug Dependence (NIDA Monograph 43). National Institute on Drug Abuse, Rockville MD, pp 159-165.

Hillhouse EW, Burden J, Jones MT (1975) The effect of various putative neurotransmitters on the release of corticotrophin releasing hormone from the hypothalamus of the rat in vitro. Neuroendocrinology 17: 1-11.

Imperato A, Mulas A, DiChiara G (1986) Nicotine preferentially stimulates dopamine release in the limbic system of freely moving rats. Eur J Pharmacol 132: 337-338. 
Introini IB, Baratti CM (1984) The impairment of retention induced by beta-endorphin in mice may be mediated by a reduction of central cholinergic activity. Behav Neural Biol 41: 152-163.

Izquierdo I, Dias RD, Souza SO, Carrasco MA, Elisabetsky E, Perry ML (1980) The role of opioid peptides in memory and learning. Behav Brain Res 1: 451-468.

Janson AM, Fuxe K, Sundstrom E, Agnati LF, Goldstein M (1988) Chronic nicotine treatment partially protects against the 1-methyl-4-phenyl-2,3,6-tetrahydropridine-induced degeneration of nigrostriatal dopamine neurons in the black mouse. Acta Physiol Scand 132: 589-491.

Kamerling SG, Wettstein JW, Sloan JW, Su FP, Martin WR (1982) Interaction between nicotine and endogenous opioid mechanisms in the unanesthetized dog. Pharmacol Biochem Behav 17: 733-740.

Karras A, Kane J (1980) Naloxone reduces cigarette smoking. Life Sci 27: 1541-1545.

Kastin AJ, Olson RD, Schally AV, Coy DH (1979) CNS effects of peripherally administered brain peptides. Life Sci 25: $401-414$.

Kellar KJ, Schwartz RD, Martino AM (1987) Nicotinic cholinergic receptor recognition. In: Martin WR, Van Loon GR, Iwamoto ET, Davis LT (Eds) Tobacco Smoking and Nicotine: A Neurobiological Approach. Plenum Press, New York, pp 467-480.

Kozlowski L (1980) The role of nicotine in the maintained use of cigarettes. Drug Merchandizing (Canada), January: 36-43.

Kozlowski LT, Harford MA (1976) On the significance of never using a drug: an example from cigarette smoking. $J$ Abnorm Psychol 85: 433-434.

Krieger DT, Martin JB (1981) Brain peptides (part II). New Engl J Med 304: 944-951.

Kuhar MJ, De Souza EB, Unnerstall JR (1986) Neurotransmitter receptor mapping by autoradiography and other methods. Annu Rev Neurosci 9: 27-59.

Kumar R, Pratt JA, Stolerman IP (1983) Characteristics of conditioned aversion produced by nicotine in rats. $B r J$ Pharmacol 79: 245-253.

Kumar R, Reavill C, Stolerman IP (1987) Nicotine cue in rats: effects of central administration of ganglionblocking drugs. Br J Pharmacol 90: 239-246.

Le Boeuf A, Lodge J, Eames PG (1978) Vasopressin and memory in Korsakoff syndrome. Lancet ii: $1370-1372$.

Legros JJ, Gilot P, Seron X, Claessen J, Adam A, Moeglen JM, Audiebert A, Berchier P (1978) Influence of vasopressin on leaming and memory. Lancet i: 41-42.

Lichtensteiger W, Hefti F, Felix D, Huwyler T, Melamed E, Schlumpf M (1982) Stimulation of nigrostriatal dopamine neurons by nicotine. Neuropharmacology 21: $963-968$.

London ED, Connally RJ, Szikszay M, Wamsley JK (1985) Distribution of central nicotine in the rat. Eur $J$ Pharmacol 110: 391-392.

London ED, Connolly RJ, Szikszay M, Wamsley JK, Diam M (1988) Effects of nicotine on local cerebral glucose utilization in the rat. J Neurosci 8: 3290-3928.

Margules DL (1979) Beta-endorphin and endoloxone: hormones of the autonomic nervous system for the conservation or expenditure of bodily resources and energy in anticipation of famine or fast. Neurosci Biobehav Rev 3: 155-162.

Marks MJ, Collins AC (1985) Tolerance, cross-tolerance, and receptors after chronic nicotine or oxotremorine. Pharmacol Biochem Behav 22: 283-291.

Marks MJ, Burch JB, Collins AC (1983) Effects of chronic nicotine infusion on tolerance development and nicotinic receptors. J Pharmacol Exp Ther 226: 817-825.

Marty MY, Erwin VG, Comell K, Zgombick $\mathrm{MM}$ (1985) Effects of nicotine on beta-endorphin, alpha-MSH, and ACTH secretion by isolated perfused mouse brains and pituitary glands, in vitro. Pharmacol Biochem Behav 22: 317-325.

Maziere M, Berger G, Masse R, Plummer D, Conar D (1979) The in vivo distribution of carbon II labeled (-) nicotine in animals: a method suitable for use in man. In: Remond A, Izand E (Eds) Electrophysiological Effects of Nicotine. Elsevier/North Holland Biomedical Press, Amsterdam, pp 31-47.

McEwen BS, deKloet ER, Rostene W (1986) Adrenal steroid receptors and actions in the nervous system. Physiol Rev 66: 1121-1188.

Meites J, Sonntag WE (1981) Hypothalamic hypophysiotropic hormones and neurotransmitter regulation: current views. Annu Rev Pharmacol Toxicol 21: 295-322.

Meltzer LT, Rosecrans JA, Aceto MD, Harris IS (1980) Discriminative stimulus properties of the optical isomers of nicotine. Psychopharmacology 68: 283-286.

Mendelson WB, Lantigua RA, Wyatt RJ, Gillin JC, Jacobs LS (1981) Piperidine enhances sleep-related and insulin-induced growth hormone secretion: further evidence for a cholinergic secretory mechanism. $J C l i n$ Endocrinol Metab 52: 409-415.

Mereu G, Yoon K-WP, Boi V, Gessa GL, Naes L, Westfall TC (1987) Preferential stimulation of ventral tegmental area dopaminergic neurons by nicotine. Eur J Pharmacol 141: 395-399. 
Millan M, Emrich H (1981) Endorphinergic systems and the response to stress. Psychother Psychosom 36: 43-56.

Munck A, Guyre PM, Holbrook NK (1984) Physiological functions of glucocorticoids in stress and their relation to pharmacological actions. Endocr Rev 5: 25-44.

Muraki T, Tokunaga Y, Nakadate T, Kato R (1979) Inhibition by cholinergic agonists of the prolactin release induced by morphine. Arch Pharmacol 308: 249-254.

Myrsten AL, Andersson K, Frankenhauser M, Elgerot A (1975) Immediate effects of cigarette smoking as related to different smoking habits. Percept Mot Skills 40: 515523.

Nelsen JM, Pelly K, Goldstein L (1975) Protection by nicotine from behavioral disruption by reticular formation stimulation in the rat. Pharmacol Biochem Behav 3: 749-754.

Nemeth-Coslett R, Griffiths RR (1986) Naloxone does not affect cigarette smoking. Psychopharmacology 89: 261-264.

Novack DH, Allen-Rowlands CF (1985) Pituitary-adrenal response to cigarette smoking (abstract). Psychosom Med 47: 78 .

Oades RD (1985) The role of noradrenaline in tuning and dopamine in switching between signals in the CNS. Neurosci Biobehav Rev 9: 261-282.

Palmer RF, Berens A (1983) Double blind study of the effects of naloxone on the pleasure of cigarette smoking (abstract). Fed Proc 42: 654.

Paton WDM, Zaimis E (1951) Paralysis of autonomic ganglia by methonium salts. Br J Pharmacol 6: 155-168.

Pauly JR, Ullman EA, Collins AC (1988) Adrenocortical hormone regulation of nicotine sensitivity in mice. Physiol Behav 44: 109-116.

Pomerleau OF, Pomerleau CS (1984) Neuroregulators and the reinforcement of smoking: towards a biobehavioral explanation. Neurosci Biobehov Rev 8: 503-513.

Pomerleau OF, Pomerleau CS (1989) A biobehavioral perspective on smoking. In: Ney T, Gale A (Eds) Smoking and Human Behaviour. John Wiley \& Sons, Chichester, England, pp 69-90.

Pomerleau OF, Fertig JB, Seyler LE, Jaffe J (1983) Neuroendocrine reactivity to nicotine in smokers. Psychopharmacology 81: 61-67.

Pomerleau CS, Pomerleau OF, Majchrzak MJ (1987) Mecamylamine pretreatment increases subsequent nicotine self-administration as indicated by changes in plasma nicotine level. Psychopharmacology 91: $391-393$.

Reaves TA, Liu HM, Qasim M, Hatward JN (1981) Vasopressin release by nicotine in the cat. Peptides 2: 13-17.

Remond A, Martinerie J, Baillon JF (1979) Nicotine intake compared with other psychophysiological situations through quantitative EEG analysis. In: Remond A, Izand C (Eds) Electrophysiological Effects of Nicotine. Elsevier Biomedical Press, Amsterdam, North Holland, pp 61-87.

Risch SC, Cohen RM, Janowsky DS, Kalin NH, Murphy DL (1980) Mood and behavioral effects of physostigmine on humans are accompanied by elevations of plasma beta-endorphin and cortisol. Science 207: 1545 1546.

Risch SC, Janowsky DS, Siever LJ, Judd LJ, Rausch J, Huey LY, Beckman KA, Cohen RM, Murphy DL (1982) Correlated cholinomimetic-stimulated beta-endorphin and prolactin release in humans. Peptides 3: 319-322.

Robinson SE (1983) Effects of specific serotonergic lesions on cholinergic neurons in the hippocampus, cortex, and striatum. Life Sci 32: 345-353.

Rose JE, Ananda S, Jarvik ME (1983) Cigarette smoking during anxiety-provoking and monotonous tasks. Addict Behov 8: 353-359.

Rosecrans JA (1971) Effects of nicotine on behavioral arousal and brain 5-hydroxytryptamine function in female rats selected for differences in activity. Eur J Pharmacol 14: 29-37.

Rosecrans JA (1987) Non-cholinergic mechanisms involved in the behavioral and stimulus effects of nicotine, and relationships to the process of nicotine dependence. In: Martin WR, Van Loon GR, Iwamoto ET, Davis LT (Eds) Tobacco Smoking and Nicotine: A Neurobiological Approach. Plenum Press, New York, pp 125-139.

Rosecrans JA (1988) In vivo approaches to studying cholinergic receptors. In: Rand MJ, Thurau $\mathrm{K}$ (Eds) The Pharmacology of Nicotine. IRL Press, Washington DC, pp 207-226.

Rosecrans JA, Meltzer CT (1981) Central sites and mechanisms of action of nicotine. Neurosci Biobehav Rev 5: 497-501.

Rosecrans JA, Hendry JS, Hong JS (1985) Biphasic effects of chronic nicotine treatment on hypothalamic immunoreactive beta-endorphin in the mouse. Pharmacol Biochem Behav 23: 141-143.

Rovira C, Cereubini E, Ben-Ari Y (1983) Opposite actions of muscarinic and nicotinic agents on hippocampal dendritic negative fields recorded in rats. Neuropharmacology 22: 239-243.

Rowell P, Winkler DL (1984) Nicotine stimulation of ${ }^{3} \mathrm{H}$-acetylcholine release from mouse cerebral cortical synaptosomes. J Neurochem 43: 1593-1598.

Russell MAH (1988) Nicotine replacement: the role of blood nicotine levels, their rate of change and nicotine tolerance. In: Pomerleau OF, Pomerleau CS (Eds) Nicotine Replacement: A Critical Evaluation. Alan R. Liss, New York, pp 63-94. 
Schwartz JH (1981) Chemical basis of synaptic transmission. In: Kandel ER, Schwartz JH (Eds) Principles of Neural Science. Elsevier/North Holland, New York, pp 106-120.

Schwartz RD, Kellar KJ (1983) Nicotinic cholinergic receptors labeled by ${ }^{3} \mathrm{H}$-acetylcholine in rat brain. Mol Pharmacol 22: 56-62.

Segal M (1978) The acetylcholine receptor in the rat hippocampus: nicotinic or muscarinic or both? Neuropharmacology 17: 661-623.

Sershen H, Reith MEA, Hashim A, Lajtha A (1984) Endogenous material in brain inhibiting ${ }^{3} \mathrm{H}$-nicotine and ${ }^{3} \mathrm{H}$ acetylcholine binding. J Neurosci Res 12: 563-569.

Seyler LE, Fertig JB, Pomerleau OF, Hunt D, Parker K (1984) The effects of smoking on ACTH and cortisol secretion. Life Sci 34: 57-65.

Seyler LE, Pomerleau OF, Fertig JB, Hunt D, Parker K (1986) Pituitary hormone response to cigarette smoking. Pharmacol Biochem Behav 24: 159-162.

Shimohama S, Taniguchi T, Fujiwara M, Kameyama M (1985) Biochemical characterization of the nicotinic cholinergic receptors in human brain: binding of (- $)^{3} \mathrm{H}$-nicotine. J Neurochem 45: 604-610.

Siegel RA, Andersson K, Fuxe K, Eneroth P, Lindbom LO, Agnati LF (1983) Rapid and discrete changes in hypothalamic catecholamine nerve terminal systems induced by audiogenic stress, and their modulation of nicotine - relationship to neuroendocrine function. Eur J Pharmacol 91: 49-56.

Silvette H, Hoff EC, Larson PS, Haag HB (1962) The actions of nicotine on central nervous system functions. Pharmacol Rev 14: 137.

Stolerman IP (1986) Could nicotine antagonists be used in smoking cessation? Br J Addict 81: 47-53.

Stolerman IP, Goldfarb T, Fink R, Jarvik ME (1973) Influencing cigarette smoking with nicotine antagonists. Psychopharmacologia 28: 247-259.

Stolerman IP, Pratt JA, Garcha HS, Giandini V, Kumar R (1983) Nicotinic cue in rats analyzed with drugs acting on cholinergic and 5-hydroxytryptamine mechanisms. Neuropharmacology 22: 1029-1038.

Svensson TH (1987) Peripheral, autonomic regulation of locus coenuleus noradrenergic neurons in brain: putative implications for psychiatry and psychopharmacology. Psychopharmacology 92: 1-7.

Svensson TH (in press) Effects of nicotine on brain catecholamine neurons as studied by electrophysiological techniques. Progr Brain Res 79.

Svensson TH, Grenhoff J, Aston-Jones G (1986) Midbrain dopamine neurons: nicotinic control of firing pattern. Soc Neurosci Abstr 12: 1154.

Tennant FS, Tarver AL, Rawson RA (1984) Clinical evaluation of mecamylamine for withdrawal from nicotine dependence. Nat Inst Drug Abuse Res Monogr 49: 239-246.

Tobin MJ, Jenouri G, Sackner MA (1982) Effects of naloxone on change in breathing pattern with smoking. Chest 82: 530-537.

Tuomisto J, Münnist6 P (1985) Neurotransmitter regulation of anterior pituitary hormone. Pharmacol Rev 37: 249-332.

United States Department of Health and Human Services (1988) The Health Consequences of Smoking: Nicotine Addiction. U.S. Government Printing Office, Washington DC (Pub. DHHS [CDC] 88-84-06).

van Ree JM, de Wied D (1981) Brain peptides and psychoactive drug effects. In: Israel Y, Glaser F, Kalant $H$, Popham R. Schmidt W, Smart R (Eds) Research Advances in Alcohol and Drug Problems, Vol VI. Plenum Press, New York, pp 67-105.

Volle RL, Koelle GB (1975) Ganglionic stimulating and blocking agents. In: Goodman LS, Gilman A (Eds) The Phammacologic Basis of Therapeutics, Sth ed. Macmillan, New York, pp 565-574.

Waeber B, Schaller MD, Nussberger J, Bussien JP, Hofbaver KG, Brunner HR (1984) Skin blood flow reduction induced by cigarette smoking: role of vasopressin. Am J Physiol 247: H895-H901.

Warburton DM, Wesnes $\mathrm{K}$ (1979) The role of electrocortical arousal in the smoking habit. In: Remond A, Izard C (Eds) Electrophysiological Effects of Nicotine. Elsevier/North Holland Biomedical Press, Amsterdam, pp 183199.

Weidenfeld J, Siegel R, Conforti N, Mizrachi R, Brenner T (1983) Effect of intracerebroventricular injection of nicotine acetylcholine receptor antibodies on $\mathrm{ACTH}$, corticosterone and prolactin secretion in the male rat. Brain Res 265: 152-156.

Weiler MH, Misgeld U, Cheong DK (1984) Presynaptic muscarinic modulation of nicotinic excitation in the rat neostriatum. Brain Res 296: 111 -120.

Weingartner H, Gold P, Ballenger J, Smallberg S, Summers R, Rubinow D, Post R, Goodwin F (1981) Effects of vasopressin on human memory functions. Science 211: 601-603.

Westfall TC (1974) Effect of nicotine and other drugs on the release of ${ }^{3} \mathrm{H}$-norepinephrine and ${ }^{3} \mathrm{H}$-dopamine from rat brain slices. Neuropharmacology 13: 693-700.

Westfall TC, Brasted M (1972) The mechanism of action of nicotine on adrenergic neurons in the perfused guineapig heart. J Pharmacol Exper Ther 182: 409-418. 
Westfall TC, Grant H, Perry H (1983) Release of dopamine and 5-hydroxytryptamine from rat striatal slices following activation of nicotinic cholinergic receptors. Gen Pharmacol 14: 321-325.

Wilkins JN, Carison HE, Van Vunakis H, Hill MA, Gritz E, Jarvik ME (1982) Nicotine from cigarette smoking increases circulating levels of cortisol, growth hormone, and prolactin in male chtonic smokers. Psychopharmacology 78: 305-308.

Wise RA (1988) The neurobiology of craving: implications for the understanding and treatment of addiction. J Abnorm Psychol 97: 118-132.

Wise RA, Bozarth MA (1987) A psychomotor stimulant theory of addiction. Psychol Rev 94: 469-491.

Wonnacott S (1987) Brain nicotine binding sites. Hum Toxicol 6: 343-353.

Wu KM, Martin WR (1983) An analysis of nicotinic and opioid processes in the medulla oblongata and nucleus ambiguus of the dog. J Pharmacol Exp Ther 227: 302-307. 